\title{
Continuation of High Goiter Prevalence in Regions with Successful Salt Iodization Program
}

\author{
UMESH KAPIL \\ Professor, Public Health Nutrition, All India Institute of Medical Sciences, Ansari Nagar, New Delhi 110 029, India. \\ umeshkapil@yahoo.com
}

I odine deficiency disorders (IDDs) refer to the spectrum of consequences of iodine deficiency in a population resulting from its deficit in soil and water. Consumption of crops and plants grown on iodine-deficient soils leads to IDD in populations solely dependent on this vegetation for their iodine requirements. When iodine intake falls below the recommended levels, the thyroid may no longer be able to synthesize sufficient amounts of thyroid hormones.

Iodine deficiency (ID) causes its impact right from the development of fetus to people of all age groups. It results in abortion, stillbirth, mental retardation, deaf-mutism, squint, dwarfism, goiter at all ages, neuromotor defects, etc. People living in areas affected by severe ID may have an intelligence quotient (IQ) of up to 13.5 points below that of those from comparable communities in areas where there is no ID. Currently, ID is the single most important preventable cause of brain damage [1].

In India, out of 582 districts in the country, surveys conducted in 324 districts have revealed that IDD is a public health problem in 263 districts, with a goiter prevalence rate of more than $10 \%$ [2]. The Government of India under the Prevention of Food Adulteration Act (PFA) stipulated that iodized salts should have a minimum of $30 \mathrm{ppm}$ iodine at the production level and $15 \mathrm{ppm}$ at the retail level. This level of salt iodization provides physiological needs of $100-150 \mu \mathrm{g} /$ day which is reflected in the median urinary iodine excretion (UIE) levels of 100-200 $\mu \mathrm{g} / \mathrm{L}$. The status of UIE levels in different regions of country has been extensively assessed by surveys over the last decade. Out 223 districts surveyed, 194 $(86 \%)$ had median UIE levels of $100 \mathrm{mcg} / \mathrm{L}$.
Similarly, out of 330 districts from which salt samples were collected and analyzed, 191 (58\%) districts had an iodine content of salt of $15 \mathrm{ppm}$ and more at beneficiary level, indicating successful implementation of National Iodine Deficiency Control Program (NIDDCP) [3].

In the current issue of the Indian Pediatrics, a study has been published from Kutch District of Gujarat [4] in which authors have found Goiter prevalence of $11.2 \%$ among primary school children in spite of presence of $(i)$ median urinary iodine excretion level of $110 \mu \mathrm{g} / \mathrm{L}$ and (ii) $92 \%$ salts samples with iodine content of $15 \mathrm{ppm}$ and more. The authors have concluded that IDD was a mild public health problem in the district. The reported continuation of high goiter prevalence in children in spite of adequate salt iodization in the region needs to be discussed. This could be due to following reasons:

1. Misclassification of goiter: According to WHO, ultrasonography provides a more precise measurement of thyroid volume compared with palpation. The specificity and sensitivity of palpation of goiter are low in grades 0 and 1 due to a high inter-observer variation [1]. Studies conducted amongst experienced examiners have revealed that the misclassification of goiter can be as high as $40 \%$. A recent study found discrepancy between palpation and ultrasound up to a level of $23.9 \%$ amongst goitrous children [5].

2. Persistence of goiter after adequate salt iodization: Elevated goiter prevalence for up to 4 years in school-aged children after successful introduction of iodized salt has been reported, 
primarily because of persistent goiter in older children [6].

3. Concomitant presence of anemia: The therapeutic response to oral iodine in goitrous children with iron deficiency anemia is impaired [7]. In Gujarat the prevalence of anemia amongst children (6-59 months) has been documented as $69.7 \%$ [8]. This could be another reason for lack of impact of iodized salt in study population.

Once a salt iodization program has been initiated, the principal impact indicator recommended in the population is the median urinary iodine level. The changes in goiter prevalence lag behind changes in iodine status, and therefore cannot be relied upon to accurately reflect current iodine intake. The thyroid size reflects iodine nutrition over months or years. Therefore, even though populations may have attained iodine sufficiency on the basis of median urinary iodine concentration, high prevalence of goiter may persist in children [9]. Also, as most iodine consumed is excreted in the urine, urinary iodine excretion level is a valid marker of a previous day's dietary iodine intake. Therefore, we must use the urinary iodine excretion levels as a biochemical marker for iodine nutritional status in a community .

Competing interests: None.

Funding: None.

\section{REFERENCES}

1. WHO/UNICEF/ICCIDD: Assessment of iodine deficiency disorders and monitoring their elimination: A guide for programme managers. Third edition. Geneva: WHO; 2007. Available at www.who.int/entity/nutrition/ publications/micronutrients/iodine_deficiency/en/ - 29k. Accessed on January 3, 2011.

2. Tiwari BK, Ray I, Malhotra RL. Policy Guidelines on National Iodine Deficiency Disorders Control Programme-Nutrition and IDD Cell. Directorate of Health Services, Ministry of Health and Family Welfare, Government of India, New Delhi, 2006; pp 1-22.

3. Kapil U. Successful efforts towards elimination of iodine deficiency disorders in India. Indian J Community Med. 2010;35:455-68.

4. Chudasama R, Patel UV, Patel RR, Verma PH. Iodine deficiency disorders in 6-12 Years - old rural primary school children in Kutch District, Gujarat. Indian Pediatr. 2010;48:453-6.

5. Vitti P, Martino E, Aghini-Lombardi F, Rago T, Antonangeli L, Maccherini D, Nanni P, et al. Thyroid volume measurement by ultrasound in children as a tool for the assessment of mild iodine deficiency. J Clin Endocrinol Metab. 1994;79:600-3.

6. Zimmermann MB, Hess SY, Adou P, Toresanni T, Wegmüller R, Hurrell RF. Thyroid size and goiter prevalence after introduction of iodized salt: a 5-y prospective study in schoolchildren in Côte d'Ivoire. Am J Clin Nutr. 2003;77:663-7.

7. Zimmermann MB, Adou P, Toresanni T, Zeder C, Hurrell R. Persistence of goiter despite oral iodine supplementation in goitrous children with iron deficiency anemia in Côte d'Ivoire. Am J Clin Nutr. 2000;71:88-93.

8. International Institute for Population Sciences (IIPS) and ORC Macro National Family Health Survey (NFHS 3) 2005-2006, Mumbai IIPS; Ajanta Offset \& Packaging Limited, New Delhi; 2006; pp 260-90.

9. Zimmermann MB. Assessing iodine status and monitoring progress of iodized salt programs. J Nutr. 2004; $134: 1673-7$. 